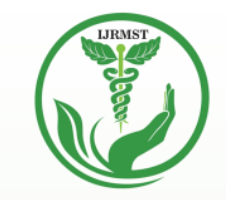

\title{
INTERNATIONAL JOURNAL OF RESEARCH IN MEDICAL
} SCIENCES \& TECHNOLOGY

e-ISSN:2455-5134; p-ISSN: 2455-9059

A Comparative Study of Serum Albumin and Body Mass Index Among Patients of Chronic Kidney Disease Undergoing Haemodialysis and Peritoneal Dialysis at S.M.S. Medical College Jaipur

*Avneesh Sharma, **Chitra Upadhyay, \#Sangeeta Meena

*Resident Doctor, **Senior Professor, \#Assistant Professor

Department of Biochemistry, SMS Medical College, Jaipur

Paper Received: $17^{\text {th }}$ February, 202 1; Paper Accepted: 19 $9^{\text {th }}$ February, 2021;

Paper Published: 20 th February, 2021

DOI: http://doi.org/10.37648/ijrmst.vl1i01.001

How to cite the article:

Avneesh Sharma, Chitra Upadhyay, Sangeeta Meena, A Comparative Study of Serum Albumin and Body Mass Index Among Patients of Chronic

Kidney Disease Undergoing

Haemodialysis and Peritoneal Dialysis at S.M.S. Medical College Jaipur, IJRMST, January-June 2021, Vol 11, 18, DOI:

http://doi.org/10.37648/ijrmst.v11i01.001

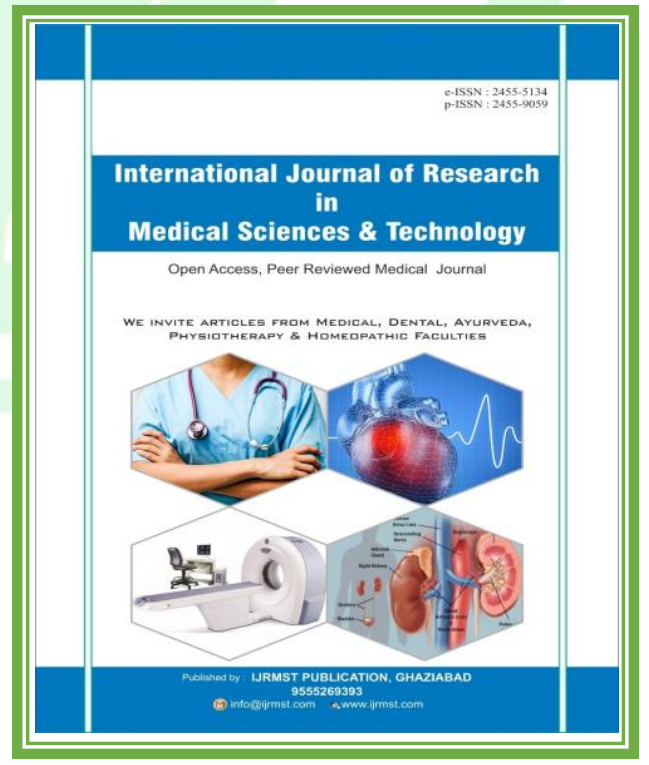




\section{ABSTRACT}

Chronic kidney disease is defined as either kidney damage or GFR $<60 \mathrm{ml} / \mathrm{min} / 1.73$ m2 Body surface area for $\geq 3$ months with or without evidence of kidney damage, irrespective of the cause. Dialysis is a procedure for taking away waste and extra water from blood, and is used mainly to provide an artificial replacement for the off tracked kidney function in people with renal failure. This study was attempted to compare the effect of Hemodialysis and Peritoneal Dialysis (continuous ambulatory type peritoneal dialysis) on Serum Albumin and Body mass index of patients of chronic kidney disease. Study was attempted in the department of biochemistry in SMS medical college, Jaipur with 60 diagnosed Chronic kidney disease cases (30 patients undergoing hemodialysis \& 30 patients undergoing peritoneal dialysis) after all essential clearance was obtained, we measured serum level of serum albumin and Body mass index. Results-Albumin was significantly higher in CKD patients undergoing Haemodialysis compare to Peritoneal Dialysis where $p$ values was $<0.03$ using unpaired student's t-test. In this study we conclude, serum albumin forecast cardiovascular, and infection-related mortality in both PD and HD patients. However, the threshold at which risk for death increases varies by dialysis type. According to this study, dietary habits, nutritional status to recommended allowance ratio were low in PD patients compared to HD patient but body mass index was found higher in PD patients due to Volume expansion. It suggests more nutritional diet may be required for PD patients.

Keywords- Albumin, Chronic Kidney Disease, Hemodialysis, Peritoneal Dialysis, Body Mass Index

\section{INTRODUCTION}

Chronic kidney disease is defined as either kidney damage or GFR < $60 \mathrm{ml} / \mathrm{min} / 1.73 \mathrm{~m}^{2}$ for $\geq 3$ months with or without evidence of kidney damage, regardless of the cause. Dialysis acts on the principles of diffusion (waste removal) and ultrafiltration (fluid removal) across a semipermeable membrane [1].

- Hemodialysis (HD): Removes waste and excess water by circulating blood outside the body through an external filter, called a dialyzer that contains a semipermeable membrane [2].

- Peritoneal dialysis (PD): Removes waste and excess water from the blood inside the body into a special dialysis solution called dialysate using peritoneal membrane as the natural semipermeable membrane [3]. There are two types of Peritoneal dialysis mainly: 1) CAPD: Continuous ambulatory peritoneal dialysis. It is done without a machine. 


\section{VOLUME: 11 , JANUARY-JUNE 2021}

2) CCPD: Continuous cycler-assisted peritoneal dialysis.

A recent clinical study has demonstrated that the serum albumin could predict the mortality of both PD and HD patients while the mortality was different in different dialysis modalities.[4,5] However, the most recent cohort studies suggested that patients treated with either $\mathrm{PD}$ or $\mathrm{HD}$ in end-stage renal disease showed remarkably similar outcomes.[6,7]

Nutritional elements are linked with high morbidity \& mortality in dialysis patients, and protein-energy wasting is considered important. The type of dialysis may affect patients' dietary habits and nutritional status, but no study has compared the dietary habits, nutrient intake of hemodialysis (HD) and peritoneal dialysis (PD) patients.

\section{OBJECTIVE}

- To assess the Lipid Profile among patients of Chronic Kidney Disease undergoing Hemodialysis \& Peritoneal Dialysis.

- To analyse and find relation (if any) of type of dialysis on lipid profile.

\section{MATERIALS AND METHODS}

- Study design: Cross Sectional hospital based comparative study.

- Study Population: 60 diagnosed Chronic Kidney Disease patients i.e. cases (30 patients undergoing hemodialysis

30 patients undergoing peritoneal dialysis)

\section{- Inclusion criteria:}

1.Chronic Kidney Disease patients undergoing Hemodialysis (HD): Adequate hemodialysis for 4 hours / 2 times weekly 2. CAPD usually four or five times daily. Maintenance HD/PD duration should be $\geq$ 3 months

- Exclusion criteria : Ischemic heart disease, nephrotic syndrome, diabetes mellitus, hepatic diseases, Thyroid disorder, familial hypercholesterolemia, recurrent myocardial infarction, unstable angina, patient taking any lipid lowering(statins) drugs.

\section{RESULTS}

\section{Albumin}

Most of the subjects of cases of chronic kidney disease undergoing dialysis were between 41-60 years In this study serum albumin is low in hemodialysis patients in 


\section{VOLUME: 1 1, JANUARY-JUNE 2021}

compare to peritoneal dialysis patients According to this study, PD patients had deficient dietary habits and later less sufficient dietary intake compared to HD patients. It is related with extensive malnutrition among PD patients, and it causes overall higher mortality in PD patients than HD patients. Results of mean albumin are shown in table and graph.

\begin{tabular}{|c|c|c|c|}
\hline & $\begin{array}{c}\text { Case HD(g/dL) } \\
\text { (Group 1) }\end{array}$ & Case PD(g/dL) & \multirow{2}{*}{ P-Value } \\
& 2.8 & 3.1 & \multirow{2}{*}{0.07} \\
\hline Min & 4.0 & 4.0 & \multirow{2}{*}{0} \\
\hline Max & 3.53 & 3.41 & \\
\hline Mean & 0.29 & 0.19 & \\
\hline SD & & & \\
\hline
\end{tabular}

Table 1: Comparison of mean Albumin level between Case HD and Case PD

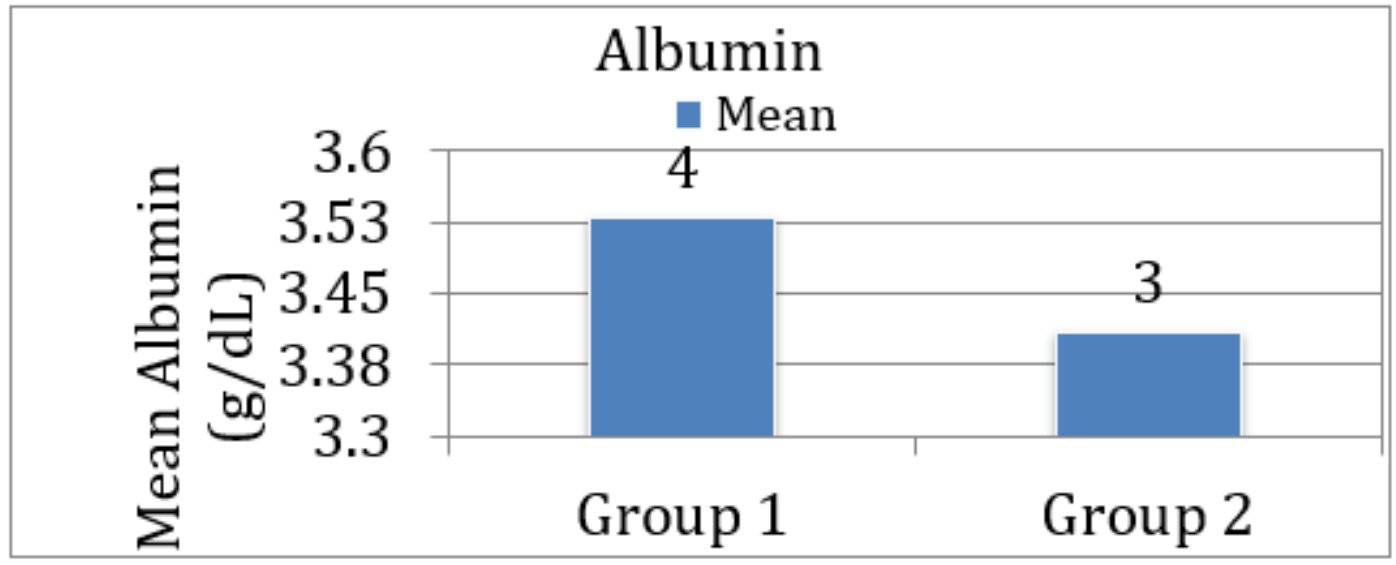

FIG:-Comparison of mean Albumin level between Case HD and Case PD 
$B M I$

BMI was higher in PD patients compared to the HD patients; this is contrary to the fact of worse nutrient intake in PD. Although we excluded the participants with well-defined oedema observed, BMI could be changed by fat mass or hydration status. We have to think about the possibility that PD patients have more volume expansion than HD patients Results are shown in table and graph.

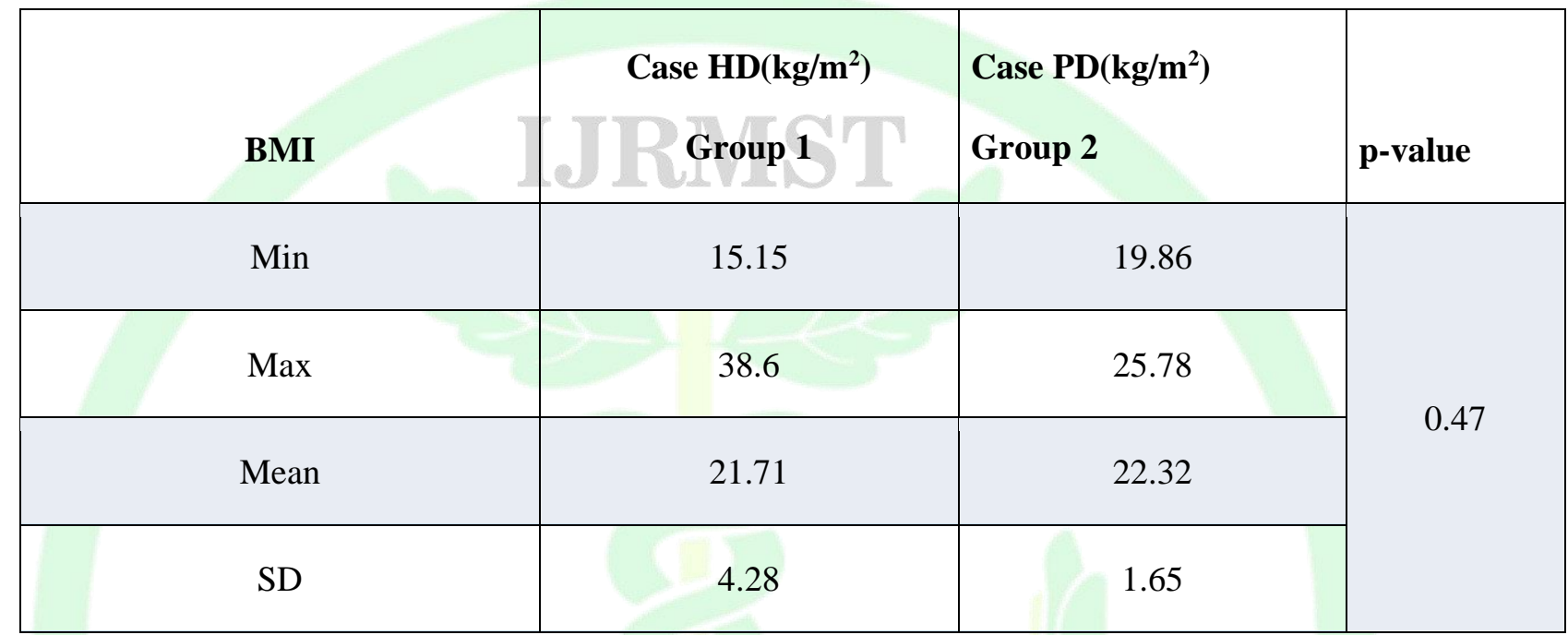

Table2: Comparison of mean BMI between Case HD and Case PD

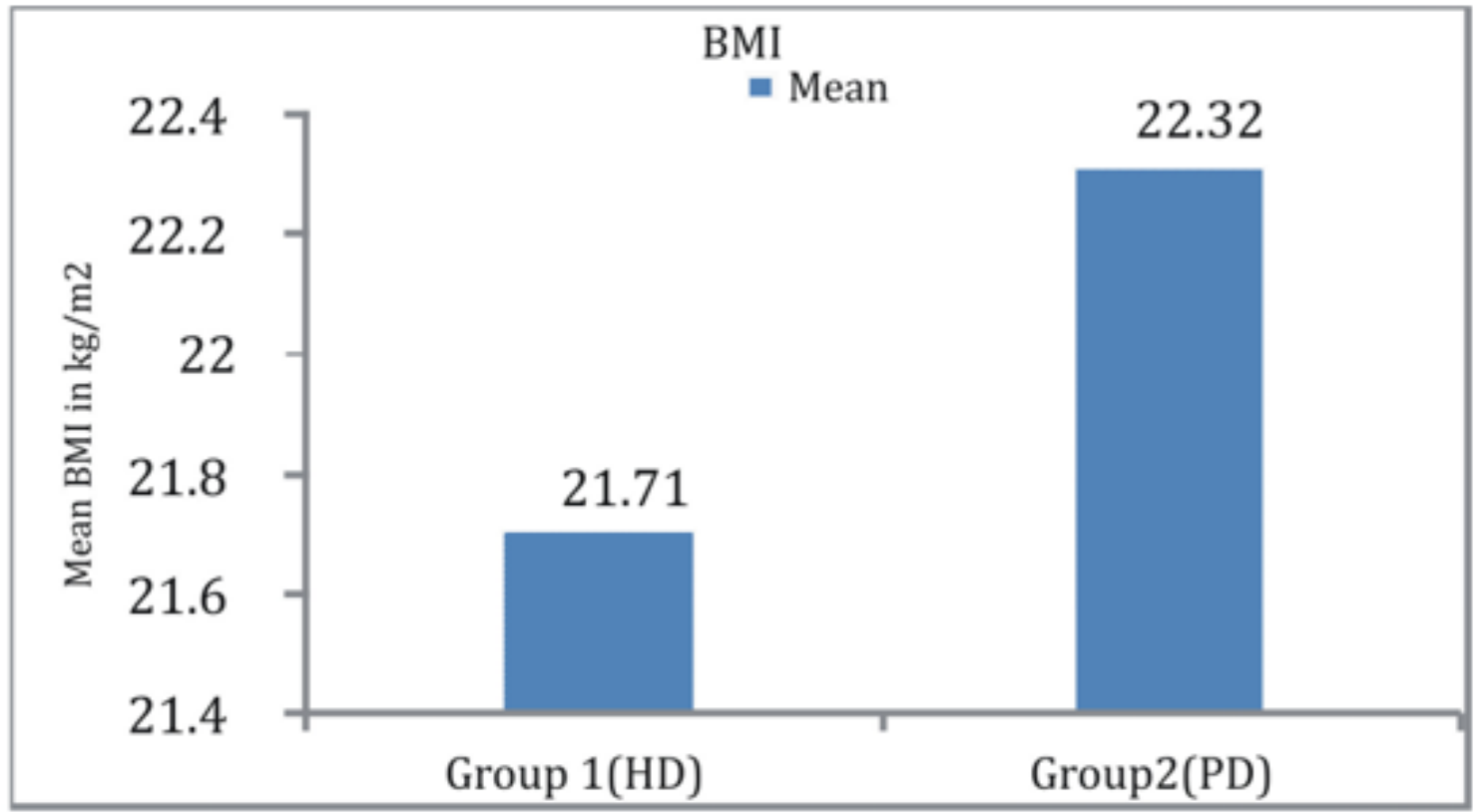

FIG 2: Comparison of mean BMI between Case HD and Case PD 


\section{DISCUSSION}

Similar type of study conducted by WanNing Wang et al in 2017; [8] found Severe RA (renal anemia) tended to be associated with manifestations of fluid overload and other risk factors. In our study, serum albumin in HD group was more than that in PD group, which may in be due to fluid overload causing dilution of albumin in PD group. Apart from this, the PD itself, using peritoneum as the semipermeable membrane, can cause albumin loss.

A recent cross-sectional study of PD patients seems to suggest that many of the patients with hypo albuminemia are volume overloaded and hypervolemia may be an additional confounding influence [9]. There are two additional considerations unique to PD patients. First, PD patients lose 5-10 g/protein per day in the dialysate effluent, which is predominantly albumin [10]. It is probably primarily for this reason that the serum albumin in PD patients is, on an average, lower than in HD patients $[11,12]$. The extent of daily peritoneal protein losses are consider a marker of systemic vascular disease load and many recent studies have shown a direct relationship between daily peritoneal protein losses and all-cause mortality $[13,14]$. Our findings are consistent with these observations. Second, peritoneal protein losses are substantially increased during episodes of peritonitis and lead to significant decreases in serum albumin [15]. As said previously, episodes of peritonitis are related with a higher cardiovascular risk and this may be one of the causes underlying the interrelation of decrease in serum albumin with higher mortality in PD patients.

BMI of both groups was almost similar, non-significant difference in group 2(PD group) $(22.32 \pm 1.65) \mathrm{kg} / \mathrm{m}^{2}$ compared to group 1 (HD group) $(21.71 \pm 4.28) \mathrm{kg} / \mathrm{m}^{2}$ Similar type of study conducted by Kim, SM. Et al in (2020).[16] found BMI was higher in PD patients compared to the HD patients, which is a contrary result to the low nutrient intake in PD. Although we excluded the participants with well-defined oedema observed, BMI could be changed by fat mass or hydration status. We have to think about the possibility that PD patients have more volume expansion than HD patients. A past study comparing the nutritional status of HD and PD groups in Korea suggested that the HD group became malnourished due to a insufficient energy intake and the PD group developed malnutrition due to insufficient protein intake. It means, intra peritoneal glucose 
absorption in dialysis fluid gives energy supplementation, but loss of protein through peritoneal fluid is more decisive for the development of malnutrition in PD patients.

\section{CONCLUSION}

PD patients may be over hydrated, although not significantly more so than HD patients. The extra fluid is not necessarily related with an expanded PlasmaVolume and is related with a low plasma albumin, which possibly encourages extra vascular fluid accumulation. This may cause an adverse effect in organ function, but the risk of normalizing may negatively affect intravascular volume, patient health, and residual renal function.

According to this study, nutritional status, dietary habits, and nutrient intake-torecommended allowance ratio were low in PD patients compared to HD patients. It suggests more thorough nutritional intercession might be needed for PD patients.

\section{REFERENCES}

1. National Kidney Foundation. KDOQI Clinical Practice Guidelines for Chronic Kidney Disease: Evaluation, Classification, and Stratification. Stratification of risk for progression of kidney disease and development of cardiovascular disease. Association of chronic kidney disease with cardiovascular disease. [Online]. 2002.

2. Ahmad S, Misra M, Hoenich N, Daugirdas J. Hemodialysis Apparatus. Handbook of Dialysis. 4th ed. New York: 2008: 59- 78.

3. Blake P, Daugirdas J. Physiology of Peritoneal Dialysis. Handbook of Dialysis. 4th ed. New York: 2008;323-338

4 Mehrotra R, Duong U, Jiwakanon S, et al. Serum albumin as a predictor of mortality in peritoneal dialysis: Comparisons with hemodialysis. Am J Kidney Dis. 2011;58:418-428.

5. Duong U, Kalantar-Zadeh K, Molnar $\mathrm{MZ}$, et al. . Mortality associated with dose response of erythropoiesisstimulating agents in hemodialysis versus peritoneal dialysis patients. Am J Nephrol. 2012;35:198-208

6 Mehrotra R, Chiu YW, Kalantar-Zadeh K, Bargman J, Vonesh E.. Similar outcomes with hemodialysis and peritoneal dialysis in patients with endstage renal disease. Arch Intern Med. 2011;171:110-118.

7. Yeates K, Zhu N, Vonesh E, Trpeski L, Blake P, Fenton S.. Hemodialysis and peritoneal dialysis are associated with similar outcomes for end-stage renal disease treatment in Canada. Nephrol Dial Transplant. 2012;27:3568-3575.

8. Wan-Ning Wang, Wen-Long Zhang, Tao Sun, Fu-Zhe Ma, Sensen Su, Zhong-Gao $\mathrm{Xu}$ Effect of peritoneal dialysis versus hemodialysis on renal anemia in renal in end stage disease patients: a meta-analysis Ren Fail. 2017; 39(1): 59-66. Published online 2016 Nov 17.

9. John B, Tan BK, Dainty S, Spanel P, Smith D, Davies SJ. Plasma volume, 


\section{VOLUME: 11 , JANUARY-JUNE 2021}

albumin, and fluid status in peritoneal dialysis patients. Clin J Am Soc Nephrol. 2010 Aug;5(8):1463-1470.

10. Westra WM, Kopple JD, Krediet RT, Appell M, Mehrotra R. Dietary protein requirements and dialysate protein losses in chronic peritoneal dialysis patients. Perit Dial Int. 2007 MarApr;27(2):192-195.

11. Yeun JY, Kaysen GA. Acute phase proteins and peritoneal dialysate albumin loss are the main determinants of serum albumin in peritoneal dialysis patients. Am J Kidney Dis. 1997 Dec;30(6):923-927.

12. Heaf JG, Sarac S, Afzal S. A high peritoneal large pore fluid flux causes hypoalbuminaemia and is a risk factor for death in peritoneal dialysis patients. Nephrol Dial Transplant. 2005 Oct;20(10):2194-2201.
13. Szeto CC, Chow KM, Lam CWK, et al. Peritoneal albumin excretion is a strong predictor of cardiovascular events in peritoneal dialysis patients: a prospective cohort study. Perit Dial Int. 2005;25:445-452.

14. Perl J, Huckvale K, Chellar M, John B, Davies SJ. Peritoneal protein clearance and not peritoneal membrane transport status predicts survival in a contemporary cohort of peritoneal dialysis patients. Clin J Am Soc Nephrol. 2009 Jul;4(7):1201-1206.

15. Blumenkrantz MJ, Gahl GM, Kopple JD, et al. Protein losses during peritoneal dialysis. Kidney Int. 1981;19:593-602.

16 Kim, SM., Kang, B., Kim, HJ. et al. Comparison of hemodialysis and peritoneal dialysis patients 'dietary behaviors. BMC Nephrol 21, 91 (2020). 